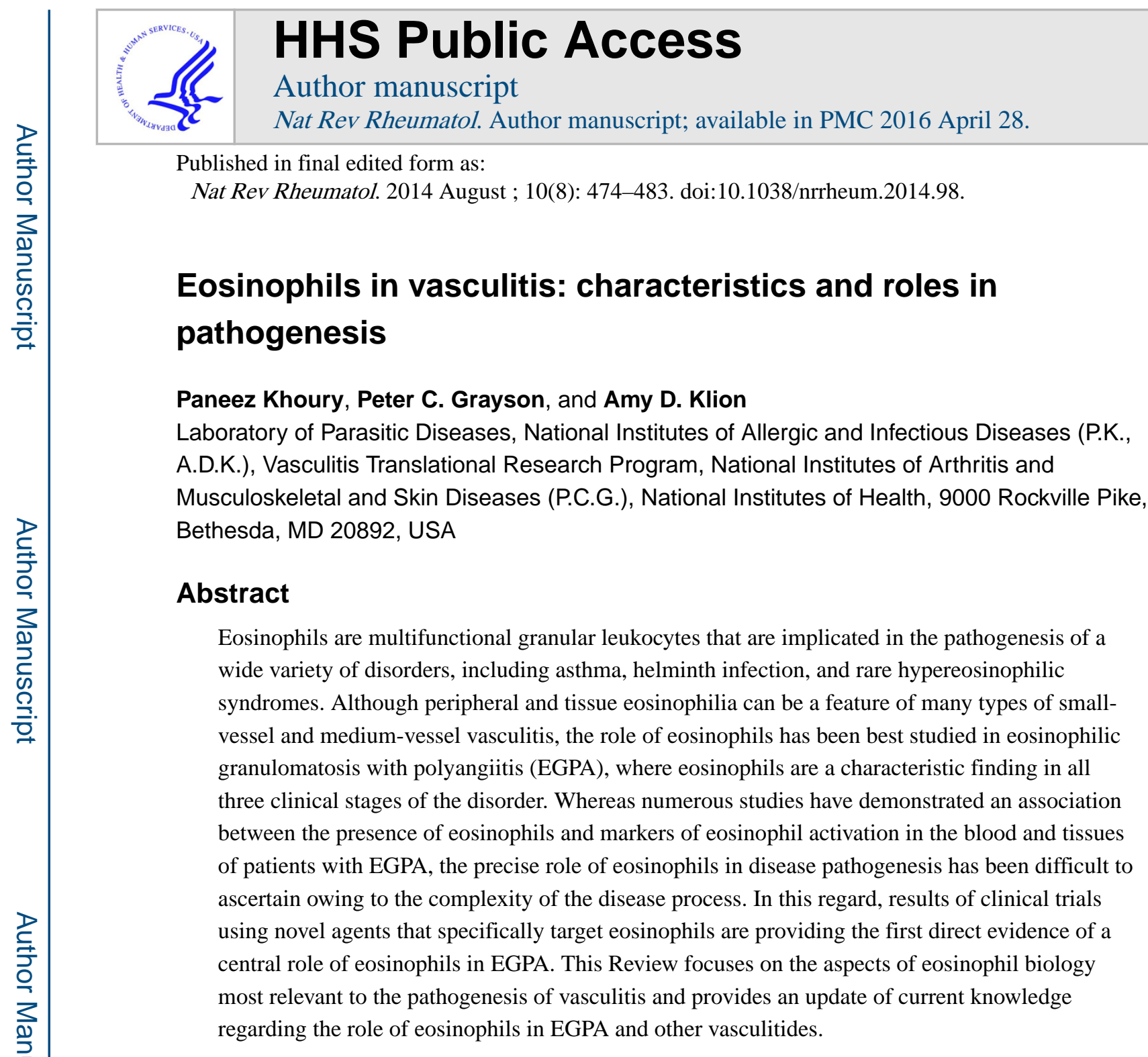

\title{
Introduction
}

Historically, the role of eosinophils in vasculitis has been studied primarily in the setting of eosinophilic granulomatosis with polyangiitis (EGPA), where periph eral and tissue eosinophilia are, by definition, increased. Eosinophilia where eosinophils account for $>10 \%$ of peripheral white blood cells and extravascular eosinophilia are two of six criteria used to distinguish EGPA from other vasculitides, according to the 1990 ACR classification criteria. ${ }^{1}$ However, as noted in the 1994 Chapel Hill nomenclature of systemic vasculitides, an abundance of eosinophils in inflammatory infiltrates is not specific to EGPA and has been reported in other types of small-vessel and medium-vessel vasculitis, most notably granulomatosis with polyangiitis (GPA). ${ }^{2}$ Eosinophilia is not a feature of large-vessel

Correspondence to: P.K. khouryp@ niaid.nih.gov.

Competing interests

The authors declare no competing interests.

Author contributions

All authors researched data for article, made a substantial contribution to discussion of content, wrote the article and reviewed/edited the manuscript before submission. 
vasculitis. Despite the presence of peripheral and tissue eosinophilia in patients with vasculitis, studies demonstrating a direct pathogenic role of eosinophils in vasculitis are lacking. The fact that there is no widely accepted animal model of eosinophilic vasculitis has been particularly limiting in this regard. Nevertheless, eosinophils have been studied extensively in other disorders and their impact on tissue damage ${ }^{3}$ and localization to sites of vascular damage in some settings ${ }^{4,5}$ have been extrapolated as evidence for their role in the pathogenesis of eosinophilic vasculitis. The contribution of the eosinophil to the pathophysiology of EGPA is now being investigated in clinical trials using therapies that specifically target eosinophils.

This Review summarizes the basic biology of eosinophils, with a focus on the features of eosinophils implicated in disease pathogenesis. The role of eosinophils and eosinophil activation in EGPA and other vasculitides is also discussed.

\section{Characteristics of eosinophils}

Peripheral blood eosinophils are terminally differentiated myeloid cells that develop in the bone marrow under the influence of a number of transcription factors, including GATAbinding factor 1 (GATA-1, also known as erythroid transcription factor), and cytokines, including IL-3, IL-5 and granulocyte-macrophage colony- stimulating factor (GM-CSF) (Figure 1). Although IL-5 is the key cytokine mediating the release of eosinophils into the bloodstream and recent data suggests that local secretion of IL- 5 by type 2 innate lymphoid cells in the tissues might have an important role in tissue accumulation of eosinophils, ${ }^{6}$ various chemokines and other soluble mediators have been implicated in directing circulating eosinophils to bind with selectins and integrins and thereby traffic into tissues. These mediators include the eotaxin chemokines (CC-chemokine ligand [CCL] 11, also known as eotaxin; CCL24, also known as eotaxin 2; and CCL26, also known as eotaxin 3), which are expressed in multiple tissues, CCL5 (also known as RANTES) produced by T cells as well as eosinophils, CCL28 produced on epithelial surfaces, ${ }^{7}$ and other nonchemokine factors such as complement factor $\mathrm{C} 5 \mathrm{a}$ and platelet activating factor.

In healthy individuals, the vast majority of eosinophils (>90\%) reside in the tissues, where they can be found in the gastrointestinal tract, spleen, lymph nodes, thymus, mammary glands and uterus. In disease states, however, eosinophils can move along chemokine gradients produced on epithelial surfaces or vascular endothelium to sites of inflammation in many different tissues (Figure 2).

\section{Eosinophil structure}

First described by Ehrlich in 1879, the eosinophil was so named because of the exuberant staining of its secondary granules with the red dye eosin. These eosinophil-specific granules contain cationic proteins including major basic protein (MBP), eosinophilic cationic protein (ECP), eosinophil peroxidase (EPO), and eosinophil derived neurotoxin (EDN), as well as a wide variety of preformed cytokines, growth factors and enzymes, all of which can be selectively released upon cell activation (reviewed in detail elsewhere ${ }^{8-10}$ ). These preformed mediators include $\mathrm{T}_{\mathrm{H}}$ 2-type cytokines (IL-4, IL-5, IL-13) and chemokines (CCL11 [eotaxin], CCL3, CCL5). Eosinophils are also characterized by primary granules, which 
contain Charcot-Leyden crystal proteins, ${ }^{11}$ and lipid bodies, which are complex inducible organelles that are the site of eicosanoid s ynthesis and release during eosinophil activation. $^{12}$

\section{Degranulation}

The eosinophil has long been thought of as a toxic effector cell that releases its granules' contents either by mechanical disruption (cytolysis) or via activating signals. This reductive viewpoint has been challenged in the past decade as more has been discovered about the mechanisms of eosinophil granule release. Eosinophils can degranulate by exocytosis, whereby cell contents are released by fusion of intracellular granules or sombrero vesicles ${ }^{13}$ with the plasma membrane. Piecemeal degranulation, by contrast, results in differential secretion of individual granule contents from activated eosinophils without disruption of the cell membrane, ${ }^{13-15}$ and is the probable mechanism by which eosinophils modulate inflammatory action in response to selective stimuli. ${ }^{16}$ Some studies have demonstrated that granules released via cytolysis can remain viable outside of the cell. These 'cell-free granules' have been shown to function as secretory organelles and can be differentially stimulated by ligands of cysteinyl leukotriene receptors ${ }^{17}$ or by ligands of cytokine receptors. ${ }^{18}$

The complex regulation of eosinophil degranulation and release of mediators in vessel walls and perivascular tissues is likely to have an important role in the pathogenesis of eosinophilic vasculitis (Figure 1). It should be noted that routine haematoxylin and eosin staining of tissues is insensitive for the detection of eosinophil granule proteins and cell-free granules. Consequently, eosinophilic tissue involvement is often underestimated in tissue biopsy specimens. ${ }^{19}$

Immunostaining with antibodies against eosinophil granule proteins has been used to demonstrate extra-cellular granule protein deposition in a variety of tissue specimens, including biopsy-obtained skin samples from patients with EGPA. ${ }^{20}$ The relative contributions of piecemeal degranulation and cytolysis to this process have been more difficult to ascertain, although a 2014 electron microscopic study of esophageal biopsy specimens from patients with eosinophilic esophagitis suggests that cytolytic release of cellfree granules could be more important than previously recognized. ${ }^{21}$

\section{The eosinophil: a jack of all trades}

In keeping with the large number and variety of surface receptors, cytokines and other mediators produced by eosinophils, it is becoming increasingly clear that the traditional paradigm of the eosinophil as a toxic effector cell is incomplete. ${ }^{22,23}$ Although eosinophils are probably important in host defense against helminths, tumour surveillance and allergic inflammation, accumulating data supports a role for eosinophils in more homeostatic functions, including tissue repair and remodelling ${ }^{24}$ and maintenance of plasma cells in the bone marrow ${ }^{25}$ and of alternatively activated macrophages in adipose tissue. ${ }^{26}$ 


\section{Eosinophil-associated tissue damage}

The eosinophil orchestrates organ-specific and disease-specific tissue damage through direct cytotoxic effects (for example, deposition of eosinophil granule proteins or release of reactive oxygen species) or indirectly as a result of recruitment and activation of other inflammatory cells. Although the resulting clinical manifestations depend, to a large degree, on the particular tissue involved, complications of eosinophil accumulation and activation include tissue fibrosis, thrombosis, and allergic inflammation.

\section{Eosinophil-mediated fibrogenesis}

Eosinophilic infiltrates and deposition of eosinophil granule proteins have been demonstrated in fibrotic tissues from many different organs ${ }^{27}$ and in a variety of clinical disorders, including asthma, ${ }^{28-31}$ eosinophilic esophagitis, ${ }^{21,32}$ and hypereosinophilic syndromes. Although these observations provide circumstantial evidence that eosinophils play a part in tissue fibrogenesis, more-direct support for this hypothesis comes from in vitro studies, in which eosinophils and eosinophil products have been shown to promote collagen synth esis and fibroblast proliferation, ${ }^{33}$ and from in vivo studies in eosinophil-deficient mice ( $\Delta$ dblGATA mice), demonstrating decreased airway extracellular matrix deposition following allergen challenge in the absence of eosinophils. ${ }^{34}$ Eosinophils seem to contribute to tissue fibrosis through multiple mechanisms, including ECP-mediated stimulation of collagen contraction ${ }^{35}$ and release of fibrogenic cytokines (such as transforming growth factor $\beta$ and IL-1 $\beta){ }^{36,37}$

\section{Eosinophils and thrombosis}

The risk of thromboembolism is increased in a range of disorders associated with marked peripheral eosinophilia, including eosinophilic myeloproliferative disorders, idiopathic hypereosinophilic syndrome, and eosinophilic vasculitis. ${ }^{38}$ Although the mechanism of eosinophil-induced hypercoagulability is not entirely clear, contributing factors probably include initiation of the clotting cascade by tissue factor (released during eosinophil degranulation), ${ }^{39}$ inhibition of vascular endothelial thrombomodulin (a potent anticoagulant) by MBP, ${ }^{40,41}$ and activation of platelets by MBP and EPO. ${ }^{42}$

\section{Eosinophils and allergic inflammation}

Peripheral eosinophilia is common in patients with allergic disorders, such as allergic rhinitis, eosinophilic esophagitis, and atopic dermatitis. Furthermore, eosinophils and eosinophil granule proteins can be demonstrated in body fluids and biopsy specimens from patients with allergic disorders including asthma. Eosinophilic inflammation and its role in asthma pathogenesis have been shown in animal models of allergic asthma, with granule proteins being shown to worsen bronchoprovocation ${ }^{28}$ and hyperresponsiveness. ${ }^{29} \mathrm{In}$ humans, ECP levels in bronchoalveolar lavage fluid correlate with asthma severity, ${ }^{30}$ and MBP is seen in mucus plugs and on epithelial surfaces of lung sections of fatal acute severe asthma (formerly referred to as status asthmaticus). ${ }^{31}$ Further validation of eosinophil granule proteins as clinical disease biomarkers in asthma and EGPA is ongoing. 


\section{Eosinophils and nerves}

Eosinophils can affect nerves and nerve function in a variety of ways. Axonal neuropathy as well as neurogenic atrophy of related muscle have been shown in nerve and muscle biopsy specimens from patients with hypereosinophilic syndromes, ${ }^{43,44}$ and a sural nerve biopsy performed in a patient with eosinophilic vasculitis showed perivascular infiltration with eosinophilia. ${ }^{45}$ Eosinophils can localize to cholinergic nerves in the setting of asthma, where they release MBP upon contact. ${ }^{46}$ They have also been shown to induce neuronal retraction in vitro via a contact-dependent mechanism. ${ }^{47}$ Taken together, these findings suggest that eosinophils can directly injure nerve tissue, although nerve ischaemia due to eosinophilic infiltration of blood vessel walls might be the predominant mechanism of nerve damage in the mononeuritis multiplex seen in EGPA.

\section{EGPA}

The role of eosinophils in vasculitis is best characterized in EGPA. In 1951, Churg and Strauss first reported a form of systemic vasculitis defined, in part, by profound blood and tissue eosinophilia (Figure 3). ${ }^{48}$ Adult-onset asthma, granulomatous inflammation and small-vessel vasculitis were also salient features in patients with this disorder. In 2012, the eponymic name of this condition was changed from Churg-Strauss Syndrome to eosinophilic granulomatosis with polyangiitis (EGPA) to promote nomenclature reflective of disease pathology. ${ }^{49}$ Although the eosinophil is considered to have a prominent role in the clinical manifestations of EGPA, the precise mechanisms of eosinophil-mediated inflammation remain to be fully elucidated.

EGPA is characterized by three overlapping phases of disease that progress at variable intervals: asthma and other allergy symptoms; tissue and blood eosinophilia; and necrotizing vasculitis. ${ }^{50}$ EGPA preferentially affects certain organ systems, including the airways, peripheral nerves, heart, kidney, and gastrointestinal tract. ${ }^{51,52}$ Antineutrophil cytoplasmic antibodies (ANCAs) have been demonstrated in approximately 30-40\% of patients with EGPA. ${ }^{53,54}$ Whether the presence or absence of ANCA defines distinct subgroups of disease pathogenesis is unclear, although constitutional symptoms, peripheral neuropathy, and glomerulonephritis are more common in patients with ANCA-positive EGPA, whereas cardiac involvement is more frequent in patients who are ANCA-negative. ${ }^{55,56}$ Despite the fact that relapses of vasculitis seem to be more frequent in ANCA-positive EGPA, mortality might be higher in ANCA-negative EGPA, presumably related to increased cardiac involvement. $^{51}$

Definitive diagnosis of EGPA relies on demonstration of vasculitis in tissue. It is unclear whether ANCA-positivity is an appropriate diagnostic surrogate for vasculitis. In the absence of proven vasculitis, the clinical and laboratory features of EGPA share considerable overlap with other hypereosinophilic syndromes, making it potentially difficult to distinguish between the conditions. ${ }^{57,58}$ There are no known causal triggers of EGPA. ${ }^{59}$ Disease onset typically occurs in people aged 40-60 years, and there is no known sex, familial, or ethnic predisposition. Candidate-gene association studies, including positive and negative disease associ ations with various HLA class II polymorphisms, ${ }^{60}$ implicate potential immunogenetic factors. 


\section{Eosinophils in EGPA pathology}

To what extent eosinophils have a primary role in the pathogenesis of EGPA, rather than a secondary role as mediators of organ damage, is unknown. Eosinophils are involved in all three stages of the pathology of EGPA.

As described above, eosinophils are implicated in the first stage of EGPA, in which asthma is the defining feature and which parallels an asthma phenotype known as nonallergic eosinophilic asthma. ${ }^{61}$ This type of asthma often develops in adulthood, is associated with chronic rhinosinusitis and/or nasal polyposis, and frequently requires treatment with high doses of systemic corticosteroids for adequate symptom control. ${ }^{62}$ Increased numbers of eosinophils in the sputum and elevated levels of sputum eosinophil granule proteins are typical. ${ }^{63}$ By definition, eosinophils are present in the second stage of EGPA—blood and tissue eosinophilia. The characteristic histopathologic findings of the third stage of EGPA, which include eosinophilic infiltration in tissue, eosinophilic vasculitis of the small arteries and veins, and eosinophilic granulomas, ${ }^{64}$ reflect the central role of eosinophils in this type of vasculitis. Granulomas in EGPA tend to have a centralized zone of eosinophilic necrosis surrounded by palisading histiocytes and multi nucleated giant cells (Figure 2). ${ }^{65}$ The different histopathologic findings of EGPA can be affected by treatment and are rarely found simultaneously in a single patient. ${ }^{66}$

Organ-specific pathology in EGPA can be the result of direct eosinophilic infiltration of the tissue and/or ischaemic damage attributable to the occlusion of small arteries by inflammatory-cell infiltration or clotting. For example, cardiac manifestations of EGPA include eosinophilic myocarditis, endomyocardial fibrosis, eosinophilic pericarditis, and myocardial infarction due to eosinophilic coronary arteritis.

\section{Immunopathogenesis of EGPA}

Although a direct role of ANCAs in disease pathogenesis is generally accepted in other types of ANCA-associated vasculitis (AAV), there is currently no evidence for a direct pathogenic role of ANCAs in EPGA. Rodent models of both myeloperoxidase (MPO)-AAV and pro-teinase 3 (PR3)-AAV have been developed but do not feature prominent eosinophilic involvement. ${ }^{67,68} \mathrm{An}$ IgE-mediated cutaneous reverse passive Arthus reaction model has been used to induce eosinophil-rich cutaneous vasculitis in wild-type C57B1/6 mice and to demonstrate a key role for P-selectin and CCL7 (monocyte chemotactic protein 3 ) in recruitment of eosinophils to cutaneous lesions, ${ }^{69}$ however, this model is not suitable for studies of systemic immunopathogenesis since the reaction is limited to the skin.

Given the lack of a suitable animal model for EGPA, disease pathogenesis is inferred largely from clinical studies. EGPA has traditionally been considered a $\mathrm{T}_{\mathrm{H}} 2$-mediated disease, from its striking early presentation with allergic inflammation to the elevation of $\mathrm{T}_{\mathrm{H}}$ 2-type cytokine levels in the circulation that are thought to contribute to the recruitment, activation, and delayed apoptosis of eosinophils. ${ }^{70,71}$ There is evidence of oligoclonal expansion in EGPA, and activated $\mathrm{CD}^{+}$type $2 \mathrm{~T}$ helper $\left(\mathrm{T}_{\mathrm{H}} 2\right)$ cells are prominent. ${ }^{72}$ Furthermore, CCL17 (also known as thymus and activation-regulated chemokine), a chemokine that 
recruits $\mathrm{T}_{\mathrm{H}} 2$ cells, is associated with active EGPA versus inactive disease and healthy controls. 57

Cytokines and chemokines that are produced by eosinophils, as well as those produced by other cell types, have been implicated in the pathogenesis of EGPA (Table 1). For example, IL-25 is a cytokine produced by multiple different cell types that can enhance $\mathrm{T}_{\mathrm{H}} 2$-type cytokine production. Eosinophils are a key source of IL-25 in EGPA, and serum concentration of IL-25 is associated with disease activity and correlates with eosinophil levels in EGPA, ${ }^{73}$ supporting the concept that the pathogenesis of EGPA probably involves contributions from interactions between the innate and adaptive immune systems. Type 2 innate lymphoid cells, which can produce large amounts of $\mathrm{T}_{\mathrm{H}}$ 2-type cytokines, including IL-5 and IL-13, have been identified in subsets of patients with nonallergic eosinophilic asthma, but have not been studied in EGPA. ${ }^{74}$

Other T-helper responses are also likely to contribute to disease pathogenesis. $\mathrm{CD} 4^{+} \mathrm{T}$-cell lines from patients with EGPA secrete high amounts of interferon- $\gamma$, a potent $\mathrm{T}_{\mathrm{H}}$ 1-type cytokine involved in vasculitis and granuloma formation, ${ }^{70}$ and type $17 \mathrm{~T}$ helper $\left(\mathrm{T}_{\mathrm{H}} 17\right)$ cells are upregulated in peripheral blood lymphocytes in active EGPA. ${ }^{75}$ Conversely, a decreased percentage of $\mathrm{CD} 4^{+} \mathrm{CD} 25^{\text {high }} \mathrm{FOXP}^{+}$regulatory $\mathrm{T}$ cells has been demonstrated in patients with active EGPA, compared with patients with asthma or chronic eosinophilic pneumonia, ${ }^{76}$ and decreases in regulatory T-cell numbers can further differentiate frequently-relapsing from seldom-relapsing EGPA. ${ }^{77}$

B-lymphocytes and humoral responses might also have a role in EGPA pathogenesis. Patients with active EGPA often have elevated serum levels of total IgE and IgE-containing immune complexes, ${ }^{78}$ and B-cell depletion can induce disease remission, reduce serum levels of IL-5, and lower eosinophil counts in EGPA. ${ }^{79}$ The clinical utility of ANCA as a longitudinal biomarker in EGPA has not been defined. However, in other forms of AAV, ANCA titres do not reliably correlate with disease activity or predict relapse ${ }^{80}$ Increased serum IgG4 levels and $\operatorname{IgG} 4: \operatorname{IgG}$ ratios have been demonstrated in patients with active EGPA in comparison with healthy individuals, patients with GPA, and patients with asthma. $^{81}$

\section{Eosinophil-related biomarkers in EGPA}

Whereas the number of circulating eosinophils correlates with disease activity in untreated EGPA, absolute eosinophil counts might not be an adequate biomarker for individual patients because the association between eosinophil counts and disease activity is altered unpredictably by treatment with glucocorticoids and other immunosuppressive therapies. ${ }^{82}$ Since glucocorticoid therapy is commonly needed to control symptoms of asthma and upper airway disease independent of systemic disease activity, ${ }^{83}$ there has been particular interest in identifying reliable biomarkers of disease activity in EGPA that are unaffected by glucocorticoids.

Sputum eosinophil counts have been proposed as a biomarker in EGPA, but the evidence is limited. In one small study, eosinophil counts and ECP levels from induced sputum were 
significantly higher in three patients with active EGPA in comparison with 10 patients with stable glucocorticoid-dependent asthma ${ }^{84}$ In asthma, sputum eosinophil counts and ECP levels are typically increased but correlate only weakly with clinical markers of asthma severity. ${ }^{85}$ Circulating levels of ECP have been associated with disease activity and peripheral eosinophil counts in EGPA. ${ }^{86}$

Serum levels of a number of cytokines, chemokines, and surface receptors involved in eosinophil activation and recruitment have been proposed as potential biomarkers of disease activity in EGPA. The best studied of these is CCL26 (eotaxin 3), an eotactic chemokine produced by epithelial and endothelial cells. In one study, serum levels of CCL26, but not CCL11 (eotaxin) or CCL24 (eotaxin 2), correlated with eosinophil counts, total IgE levels, and acute inflammatory markers in 40 patients with EGPA and was not elevated in the serum of individuals with other eosinophilic or vasculitic disorders. ${ }^{87}$ The utility of serum CCL26 levels for the diagnosis of active EGPA (sensitivity of $87.5 \%$ and specificity of $98.6 \%$ ) was confirmed in a second study by the same authors. ${ }^{88}$ Although serum levels of CCL1 $17^{89}$ and soluble IL-2 receptor ${ }^{90}$ have been reported to be increased in the setting of active EGPA, they are also elevated in other eosinophilic disorders. ${ }^{57}$

Eicosanoids, a family of hormones that includes prostaglandins, thromboxanes, and leukotrienes, might have proinflammatory effects in EGPA and other airway diseases. Casecontrol studies have linked EGPA onset to exposure to leukotriene receptor antagonists (LTRAs); however, these studies are subject to potential selection bias on the basis of asthma severity, a possible steroid-sparing effect upon initiation of medications used to treat asthma (including LRTAs) that could 'unmask' latent EGPA. ${ }^{91}$ Urinary leukotriene $\mathrm{E}_{4}$ correlates with disease activity in both EGPA and asthma, ${ }^{92}$ and an arachidonic acid metabolite, 12 hydroxyl- eicosatetraenoic acid (12-HETE), could be a disease-specific biomarker in EGPA. In one study, exhaled breath condensate from patients with EGPA was characterized by markedly elevated levels of 12-HETE in comparison with patients with asthma, hypereosinophilic syndromes or healthy individuals, and levels of 12-HETE were also elevated in bronchoalveolar lavage fluid from patients with EGPA compared with patients with asthma; 12-HETE levels were not affected by concomitant use or dose of glucocorticoids. ${ }^{93}$

\section{Therapeutics in EGPA}

To date, no randomized controlled interventional trials have been performed in EGPA; therefore, treatment recommendations are based upon small pilot studies, expert opinion, and/or extrapolation from efficacious therapies in other forms of vasculitis. ${ }^{94-97}$ In theory, therapies that modulate the production, recruitment, or survival of eosinophils might have efficacy in EGPA. Glucocorticoids reduce the number of eosinophils in the blood and tissues through mechanisms that promote cell death and clearance, and are a mainstay of therapy for EGPA. ${ }^{98}$

The five-factor score (FFS), which is used to evaluate prognosis at diagnosis, can be used to guide therapeutic decisions in EGPA. ${ }^{99}$ In patients with a poor prognosis, defined as a FFS $\geq 1$, intensive therapy with both glucocorticoids and cyclophosphamide has been shown to 
improve survival. ${ }^{99}$ Medications such as azathioprine and methotrexate are also used as steroid-sparing agents in milder disease or for maintenance of remission. IFN-a therapy can inhibit eosinophil recruitment ${ }^{100}$ and has been used to induce remission in EGPA. However, given the numerous adverse effects and lack of convincing efficacy data, therapeutic use of IFN- $a$ has been restricted to patients unable to tolerate conventional immunosuppressive therapies. ${ }^{101}$ Efficacy of rituximab as induction therapy in both ANCA-positive and ANCAnegative cases of EGPA has been reported in small case series, ${ }^{79,102}$ highlighting the potential importance of humoral immunity in EGPA. Adjunctive therapy with intravenous immunoglobulin might also be beneficial. ${ }^{103}$

As previously mentioned, IL-5 is an eosinophil- specific cytokine that has key roles in the proliferation and maturation of eosinophil progenitors and in the migration and survival of mature eosinophils. Many of the commercially available agents used to treat EGPA can reduce IL-5 levels, including glucocorticoids, ${ }^{104}$ rituximab, ${ }^{79}$ and IFN-a, ${ }^{100}$ and promising early results are emerging from studies using a humanized anti-IL-5 antibody, mepolizumab, as remission maintenance therapy in EGPA. ${ }^{105-107}$ A large multicentre trial of mepolizumab is currently underway. ${ }^{108}$

\section{Eosinophils in other vasculitides}

Peripheral and tissue eosinophilia has been reported in AAV other than EGPA, typically at mild to moderate levels. ${ }^{109-115}$ In fact, some patients with GPA fulfill the 1990 ACR criteria for EGPA on the basis of eosinophilia and overlapping clinical symptoms. ${ }^{114}$ Eosinophilia has also been reported in Kawasaki disease, with mild peripheral eosinophilia noted in 22 $36 \%$ of patients at the time of diagnosis and prominent eosinophilic infiltrate demonstrated in the epicardial microvasculature of patients who died from Kawasaki disease. ${ }^{116-118}$ Druginduced vasculitis can also feature prominent eosinophilia, ${ }^{4}$ and a high degree of tissue eosinophilia in biopsy-obtained samples of purpuric lesions has been proposed as a means to differentiate this condition from other forms of cutaneous small-vessel vasculitis. ${ }^{119}$

Despite the association between eosinophilia and vasculitides other than EGPA, the role of eosinophils in disease pathogenesis in these conditions remains unclear since eosinophilia is not universally present and few studies have been performed in patients with eosinophilia and vasculitides other than EGPA. Further complicating the issue, some of the few studies that have explored eosinophilia in GPA have relied on assays of ECP or EDN in tissue or body fluids to document eosinophil activation. ${ }^{110,115}$ Whereas these assays might be useful in the setting of EGPA, where there is an overwhelming predominance of eosinophils, ECP and EDN are also present in neutrophils, ${ }^{120}$ which are known to be pathogenic in AAV. ${ }^{121}$

\section{Conclusions}

Although the complexity of eosinophil biology is emerging within the context of eosinophilic diseases, including EGPA, significant gaps in our understanding of the role of eosinophils in vasculitis remain. Accumulating data from clinical studies of eosinophilassociated biomarkers and novel therapeutics that specifically target eosinophils are likely to provide new insights in this regard. 


\section{Acknowledgments}

This work was supported in whole or in part by the Division of Intramural Research, National Institute of Allergy and Infectious Diseases, NIH. The authors thank C. R. Lee for assistance with the preparation of Figure 3.

\section{References}

1. Masi AT, et al. The American College of Rheumatology 1990 criteria for the classification of Churg-Strauss syndrome (allergic granulomatosis and angiitis). Arthritis Rheum. 1990; 33:10941100. [PubMed: 2202307]

2. Jennette JC, et al. Nomenclature of systemic vasculitides. Proposal of an international consensus conference. Arthritis Rheum. 1994; 37:187-192. [PubMed: 8129773]

3. Gleich GJ, Adolphson CR. The eosinophilic leukocyte: structure and function. Adv Immunol. 1986; 39:177-253. [PubMed: 3538819]

4. Mullick FG, McAllister HA Jr, Wagner BM, Fenoglio JJ Jr. Drug related vasculitis Clinicopathologic correlations in 30 patients. Hum Pathol. 1979; 10:313-325. [PubMed: 468217]

5. Robinowitz M, Virmani R, McAllister HAJ. Spontaneous coronary artery dissection and eosinophilic inflammation: a cause and effect relationship? Am J Med. 1982; 72:923-928. [PubMed: 7091163]

6. Nussbaum JC, et al. Type 2 innate lymphoid cells control eosinophil homeostasis. Nature. 2013; 502:245-248. [PubMed: 24037376]

7. John AE, Thomas MS, Berlin AA, Lukacs NW. Temporal production of CCL28 corresponds to eosinophil accumulation and airway hyperreactivity in allergic airway inflammation. Am J Pathol. 2005; 166:345-353. [PubMed: 15681819]

8. Hogan SP, et al. Eosinophils: biological properties and role in health and disease. Clin Exp Allergy. 2008; 38:709-750. [PubMed: 18384431]

9. Moqbel R, Lacy P. New concepts in effector functions of eosinophil cytokines. Clin Exp Allergy. 2000; 30:1667-1671. [PubMed: 11122202]

10. Walsh GM. Eosinophil granule proteins and their role in disease. Curr Opin Hematol. 2001; 8:2833. [PubMed: 11138623]

11. Dvorak AM, Letourneau L, Login GR, Weller PF, Ackerman SJ. Ultrastructural localization of the Charcot-Leyden crystal protein (lysophospholipase) to a distinct crystalloid-free granule population in mature human eosinophils. Blood. 1988; 72:150-158. [PubMed: 2455566]

12. Melo RC, Paganoti GF, Dvorak AM, Weller PF. The internal architecture of leukocyte lipid body organelles captured by three-dimensional electron microscopy tomography. PLoS ONE. 2013; 8:e59578. [PubMed: 23555714]

13. Melo RC, et al. Vesicle-mediated secretion of human eosinophil granule-derived major basic protein. Lab Invest. 2009; 89:769-781. [PubMed: 19398958]

14. Melo RC, Perez SA, Spencer LA, Dvorak AM, Weller PF. Intragranular vesiculotubular compartments are involved in piecemeal degranulation by activated human eosinophils. Traffic. 2005; 6:866-879. [PubMed: 16138901]

15. Spencer LA, et al. Cytokine receptor-mediated trafficking of preformed IL-4 in eosinophils identifies an innate immune mechanism of cytokine secretion. Proc Natl Acad Sci USA. 2006; 103:3333-3338. [PubMed: 16492782]

16. Spencer LA, et al. Human eosinophils constitutively express multiple $\mathrm{T}_{\mathrm{H}} 1, \mathrm{~T}_{\mathrm{H}} 2$, and immunoregulatory cytokines that are secreted rapidly and differentially. J Leukoc Biol. 2009; 85:117-123. [PubMed: 18840671]

17. Neves JS, Radke AL, Weller PF. Cysteinyl leukotrienes acting via granule membrane-expressed receptors elicit secretion from within cell-free human eosinophil granules. J Allergy Clin Immunol. 2010; 125:477-482. [PubMed: 20159258]

18. Neves JS, et al. Eosinophil granules function extracellularly as receptor-mediated secretory organelles. Proc Natl Acad Sci USA. 2008; 105:18478-18483. [PubMed: 19017810]

19. Wright BL, Leiferman KM, Gleich GJ. Eosinophil granule protein localization in eosinophilic endomyocardial disease. N Engl J Med. 2011; 365:187-188. [PubMed: 21751935] 
20. Drage LA, et al. Evidence for pathogenic involvement of eosinophils and neutrophils in ChurgStrauss syndrome. J Am Acad Dermatol. 2002; 47:209-216. [PubMed: 12140466]

21. Saffari, H., et al. Electron microscopy elucidates eosinophil degranulation patterns in patients with eosinophilic esophagitis. J Allergy Clin Immunol. 2014. http://dx.doi.org/10.1016/j.jaci. 2013.11.024

22. Blanchard C, Rothenberg ME. Biology of the eosinophil. Adv Immunol. 2009; 101:81-121. [PubMed: 19231593]

23. Rosenberg HF, Dyer KD, Foster PS. Eosinophils: changing perspectives in health and disease. Nat Rev Immunol. 2013; 13:9-22. [PubMed: 23154224]

24. Lee JJ, Jacobsen EA, McGarry MP, Schleimer RP, Lee NA. Eosinophils in health and disease: the LIAR hypothesis. Clin Exp Allergy. 2010; 40:563-575. [PubMed: 20447076]

25. Chu VT, et al. Eosinophils are required for the maintenance of plasma cells in the bone marrow. Nat Immunol. 2011; 12:151-159. [PubMed: 21217761]

26. Wu D, et al. Eosinophils sustain adipose alternatively activated macrophages associated with glucose homeostasis. Science. 2011; 332:243-247. [PubMed: 21436399]

27. Noguchi H, Kephart GM, Colby TV, Gleich GJ. Tissue eosinophilia and eosinophil degranulation in syndromes associated with fibrosis. Am J Pathol. 1992; 140:521-528. [PubMed: 1739138]

28. Gundel RH, Letts LG, Gleich GJ. Human eosinophil major basic protein induces airway constriction and airway hyperresponsiveness in primates. J Clin Invest. 1991; 87:1470-1473. [PubMed: 2010556]

29. Fryer AD, Adamko DJ, Yost BL, Jacoby DB. Effects of inflammatory cells on neuronal M2 muscarinic receptor function in the lung. Life Sci. 1999; 64:449-455. [PubMed: 10069509]

30. Bousquet J, et al. Indirect evidence of bronchial inflammation assessed by titration of inflammatory mediators in BAL fluid of patients with asthma. J Allergy Clin Immunol. 1991; 88:649-660. [PubMed: 1918730]

31. Filley WV, Holley KE, Kephart GM, Gleich GJ. Identification by immunofluorescence of eosinophil granule major basic protein in lung tissues of patients with bronchial asthma. Lancet. 1982; 2:11-16. [PubMed: 6177986]

32. Kephart GM, et al. Marked deposition of eosinophil-derived neurotoxin in adult patients with eosinophilic esophagitis. Am J Gastroenterol. 2010; 105:298-307. [PubMed: 19888203]

33. Levi-Schaffer F, et al. Human eosinophils regulate human lung- and skin-derived fibroblast properties in vitro: a role for transforming growth factor beta (TGF- $\beta$ ). Proc Natl Acad Sci USA. 1999; 96:9660-9665. [PubMed: 10449750]

34. Humbles AA, et al. A critical role for eosinophils in allergic airways remodeling. Science. 2004; 305:1776-1779. [PubMed: 15375268]

35. Zagai U, Skold CM, Trulson A, Venge P, Lundahl J. The effect of eosinophils on collagen gel contraction and implications for tissue remodelling. Clin Exp Immunol. 2004; 135:427-433. [PubMed: 15008974]

36. Gomes I, et al. Eosinophil-fibroblast interactions induce fibroblast IL-6 secretion and extracellular matrix gene expression: implications in fibrogenesis. J Allergy Clin Immunol. 2005; 116:796-804. [PubMed: 16210053]

37. Zagai U, Dadfar E, Lundahl J, Venge P, Skold CM. Eosinophil cationic protein stimulates TGF- $\beta 1$ release by human lung fibroblasts in vitro. Inflammation. 2007; 30:153-160. [PubMed: 17587163]

38. Ames PR, Margaglione M, Mackie S, Alves JD. Eosinophilia and thrombophilia in Churg-Strauss syndrome: a clinical and pathogenetic overview. Clin Appl Thromb Hemost. 2010; 16:628-636. [PubMed: 19833618]

39. Moosbauer $\mathrm{C}$, et al. Eosinophils are a major intravascular location for tissue factor storage and exposure. Blood. 2007; 109:995-1002. [PubMed: 17003379]

40. Mukai HY, Ninomiya H, Ohtani K, Nagasawa T, Abe T. Major basic protein binding to thrombomodulin potentially contributes to the thrombosis in patients with eosinophilia. Br J Haematol. 1995; 90:892-899. [PubMed: 7669668]

41. Slungaard A, Vercellotti GM, Tran T, Gleich GJ, Key NS. Eosinophil cationic granule proteins impair thrombomodulin function. A potential mechanism for thromboembolism in hypereosinophilic heart disease. J Clin Invest. 1993; 91:1721-1730. [PubMed: 8386194] 
42. Rohrbach MS, Wheatley CL, Slifman NR, Gleich GJ. Activation of platelets by eosinophil granule proteins. J Exp Med. 1990; 172:1271-1274. [PubMed: 2212954]

43. Dorfman LJ, Ransom BR, Forno LS, Kelts A. Neuropathy in the hypereosinophilic syndrome. Muscle Nerve. 1983; 6:291-298. [PubMed: 6866008]

44. Wichman A, Buchthal F, Pezeshkpour GH, Fauci AS. Peripheral neuropathy in hypereosinophilic syndrome. Neurology. 1985; 35:1140-1145. [PubMed: 2991813]

45. Nascimento O, De Freitas M, Chimelli L, Scaravilli F. Peripheral neuropathy in hypereosinophilic syndrome with vasculitis. Arq Neuropsiquiatr. 1991; 49:450-455. [PubMed: 1668782]

46. Costello RW, et al. Localization of eosinophils to airway nerves and effect on neuronal M2 muscarinic receptor function. Am J Physiol. 1997; 273:L93-L103. [PubMed: 9252545]

47. Kingham PJ, et al. Effects of eosinophils on nerve cell morphology and development: the role of reactive oxygen species and p38 MAP kinase. Am J Physiol Lung Cell Mol Physiol. 2003; 285:L915-L924. [PubMed: 12794004]

48. Churg J, Strauss L. Allergic granulomatosis, allergic angiitis, and periarteritis nodosa. Am J Pathol. 1951; 27:277-301. [PubMed: 14819261]

49. Jennette JC, et al. 2012 revised International Chapel Hill Consensus Conference Nomenclature of Vasculitides. Arthritis Rheum. 2013; 65:1-11. [PubMed: 23045170]

50. Lanham JG, Elkon KB, Pusey CD, Hughes GR. Systemic vasculitis with asthma and eosinophilia: a clinical approach to the Churg-Strauss syndrome. Medicine (Baltimore). 1984; 63:65-81. [PubMed: 6366453]

51. Comarmond C, et al. Eosinophilic granulomatosis with polyangiitis (Churg-Strauss): clinical characteristics and long-term followup of the 383 patients enrolled in the French Vasculitis Study Group cohort. Arthritis Rheum. 2013; 65:270-281. [PubMed: 23044708]

52. Grayson PC, et al. New features of disease after diagnosis in 6 forms of systemic vasculitis. J Rheumatol. 2013; 40:1905-1912. [PubMed: 23908447]

53. Sable-Fourtassou R, et al. Antineutrophil cytoplasmic antibodies and the Churg-Strauss syndrome. Ann Intern Med. 2005; 143:632-638. [PubMed: 16263885]

54. Sinico RA, et al. Prevalence and clinical significance of antineutrophil cytoplasmic antibodies in Churg-Strauss syndrome. Arthritis Rheum. 2005; 52:2926-2935. [PubMed: 16142760]

55. Sinico RA, Bottero P, Guillevin L. Antineutrophil cytoplasmic autoantibodies and clinical phenotype in patients with Churg-Strauss syndrome. J Allergy Clin Immunol. 2012; 130:1440. [PubMed: 23098809]

56. Moosig F, et al. A vasculitis centre based management strategy leads to improved outcome in eosinophilic granulomatosis and polyangiitis (Churg-Strauss, EGPA): monocentric experiences in 150 patients. Ann Rheum Dis. 2013; 72:1011-1017. [PubMed: 22887848]

57. Khoury P, et al. Serum biomarkers are similar in Churg-Strauss syndrome and hypereosinophilic syndrome. Allergy. 2012; 67:1149-1156. [PubMed: 22775568]

58. Valent $P$, et al. Pathogenesis and classification of eosinophil disorders: a review of recent developments in the field. Expert Rev Hematol. 2012; 5:157-176. [PubMed: 22475285]

59. Mahr A, et al. Eosinophilic granulomatosis with polyangiitis (Churg-Strauss): evolutions in classification, etiopathogenesis, assessment and management. Curr Opin Rheumatol. 2014; 26:1623. [PubMed: 24257370]

60. Vaglio A, et al. HLA-DRB4 as a genetic risk factor for Churg-Strauss syndrome. Arthritis Rheum. 2007; 56:3159-3166. [PubMed: 17763415]

61. Wenzel SE. Asthma phenotypes: the evolution from clinical to molecular approaches. Nat Med. 2012; 18:716-725. [PubMed: 22561835]

62. Miranda C, Busacker A, Balzar S, Trudeau J, Wenzel SE. Distinguishing severe asthma phenotypes: role of age at onset and eosinophilic inflammation. J Allergy Clin Immunol. 2004; 113:101-108. [PubMed: 14713914]

63. Nair P, et al. Eosinophil peroxidase in sputum represents a unique biomarker of airway eosinophilia. Allergy. 2013; 68:1177-1184. [PubMed: 23931643] 
64. Lie JT. Illustrated histopathologic classification criteria for selected vasculitis syndromes. American College of Rheumatology Subcommittee on Classification of Vasculitis. Arthritis Rheum. 1990; 33:1074-1087. [PubMed: 1975173]

65. Katzenstein AL. Diagnostic features and differential diagnosis of Churg-Strauss syndrome in the lung. A review. Am J Clin Pathol. 2000; 114:767-772. [PubMed: 11068552]

66. Churg A. Recent advances in the diagnosis of Churg-Strauss syndrome. Mod Pathol. 2001; 14:1284-1293. [PubMed: 11743052]

67. Xiao H, et al. Antineutrophil cytoplasmic autoantibodies specific for myeloperoxidase cause glomerulonephritis and vasculitis in mice. J Clin Invest. 2002; 110:955-963. [PubMed: 12370273]

68. Salama AD, Little MA. Animal models of antineutrophil cytoplasm antibody-associated vasculitis. Curr Opin Rheumatol. 2012; 24:1-7. [PubMed: 22089094]

69. Ishii T, et al. Establishment of experimental eosinophilic vasculitis by IgE-mediated cutaneous reverse passive Arthus reaction. Am J Pathol. 2009; 174:2225-2233. [PubMed: 19389931]

70. Kiene M, et al. Elevated interleukin-4 and interleukin-13 production by $\mathrm{T}$ cell lines from patients with Churg-Strauss syndrome. Arthritis Rheum. 2001; 44:469-473. [PubMed: 11229479]

71. Jakiela $B$, et al. Increased production of IL-5 and dominant $\mathrm{T}_{\mathrm{H}}$ 2-type response in airways of Churg-Strauss syndrome patients. Rheumatology (Oxford). 2012; 51:1887-1893. [PubMed: 22772323]

72. Muschen M, et al. Involvement of soluble CD95 in Churg-Strauss syndrome. Am J Pathol. 1999; 155:915-925. [PubMed: 10487849]

73. Terrier B, et al. Interleukin-25: a cytokine linking eosinophils and adaptive immunity in ChurgStrauss syndrome. Blood. 2010; 116:4523-4531. [PubMed: 20729468]

74. Brusselle GG, Maes T, Bracke KR. Eosinophils in the spotlight: eosinophilic airway inflammation in nonallergic asthma. Nat Med. 2013; 19:977-979. [PubMed: 23921745]

75. Jakiela $\mathrm{B}$, et al. Both $\mathrm{T}_{\mathrm{H}} 2$ and $\mathrm{T}_{\mathrm{H}} 17$ responses are involved in the pathogenesis of Churg-Strauss syndrome. Clin Exp Rheumatol. 2011; 29(Suppl 64):S23-S34. [PubMed: 21470488]

76. Saito H, Tsurikisawa N, Tsuburai T, Akiyama K. Involvement of regulatory T cells in the pathogenesis of Churg-Strauss syndrome. Int Arch Allergy Immunol. 2008; 146(Suppl 1):73-76. [PubMed: 18504411]

77. Tsurikisawa N, Saito H, Oshikata C, Tsuburai T, Akiyama K. Decreases in the numbers of peripheral blood regulatory $\mathrm{T}$ cells, and increases in the levels of memory and activated B cells, in patients with active eosinophilic granulomatosis and polyangiitis. J Clin Immunol. 2013; 33:965976. [PubMed: 23624693]

78. Manger BJ, et al. IgE-containing circulating immune complexes in Churg-Strauss vasculitis. Scand J Immunol. 1985; 21:369-373. [PubMed: 3890149]

79. Pepper RJ, et al. Rituximab is effective in the treatment of refractory Churg-Strauss syndrome and is associated with diminished T-cell interleukin-5 production. Rheumatology (Oxford). 2008; 47:1104-1105. [PubMed: 18492710]

80. Tomasson G, Grayson PC, Mahr AD, Lavalley M, Merkel PA. Value of ANCA measurements during remission to predict a relapse of ANCA-associated vasculitis-a meta-analysis. Rheumatology (Oxford). 2012; 51:100-109. [PubMed: 22039267]

81. Vaglio A, et al. IgG4 immune response in Churg-Strauss syndrome. Ann Rheum Dis. 2012; 71:390-393. [PubMed: 22121132]

82. Grayson PC, et al. Clinical value of commonly-measured laboratory tests in eosinophilic granulomatosis with polyangiitis (Churg-Strauss) [abstract \#756]. Arthritis Rheum. 2013; 65(Suppl 10):S319.

83. Monach PA. Biomarkers in vasculitis. Curr Opin Rheumatol. 2014; 26:24-30. [PubMed: 24257367]

84. Meziane H, Maakel ML, Vachier I, Bousquet J, Chanez P. Sputum eosinophilia in Churg-Strauss syndrome. Respir Med. 2001; 95:799-801. [PubMed: 11601744]

85. Cianchetti S, et al. Are sputum ECP and eosinophils differently associated with clinical and functional findings of asthma? Clin Exp Allergy. 2013; 44:673-680. [PubMed: 24245689] 
86. Guilpain P, et al. Serum eosinophil cationic protein: a marker of disease activity in Churg-Strauss syndrome. Ann N Y Acad Sci. 2007; 1107:392-399. [PubMed: 17804567]

87. Polzer K, et al. Eotaxin-3 is involved in Churg-Strauss syndrome-a serum marker closely correlating with disease activity. Rheumatology (Oxford). 2008; 47:804-808. [PubMed: 18397958]

88. Zwerina J, et al. Eotaxin-3 in Churg-Strauss syndrome: a clinical and immunogenetic study. Rheumatology (Oxford). 2011; 50:1823-1827. [PubMed: 21266446]

89. Dallos T, et al. CCL17/thymus and activation-related chemokine in Churg-Strauss syndrome. Arthritis Rheum. 2010; 62:3496-3503. [PubMed: 20669282]

90. Schmitt WH, et al. Churg-Strauss syndrome: serum markers of lymphocyte activation and endothelial damage. Arthritis Rheum. 1998; 41:445-452. [PubMed: 9506572]

91. Hauser T, et al. The leucotriene receptor antagonist montelukast and the risk of Churg-Strauss syndrome: a case-crossover study. Thorax. 2008; 63:677-682. [PubMed: 18276721]

92. Higashi N, et al. Clinical features of asthmatic patients with increased urinary leukotriene $\mathrm{E}_{4}$ excretion (hyperleukotrienuria): involvement of chronic hyperplastic rhinosinusitis with nasal polyposis. J Allergy Clin Immunol. 2004; 113:277-283. [PubMed: 14767442]

93. Szczeklik W, et al. 12-hydroxy-eicosatetraenoic acid (12-HETE): a biomarker of Churg-Strauss syndrome. Clin Exp Allergy. 2012; 42:513-522. [PubMed: 22417211]

94. Mukhtyar C, et al. EULAR recommendations for the management of primary small and medium vessel vasculitis. Ann Rheum Dis. 2009; 68:310-317. [PubMed: 18413444]

95. Jayne D, et al. A randomized trial of maintenance therapy for vasculitis associated with antineutrophil cytoplasmic autoantibodies. N Engl J Med. 2003; 349:36-44. [PubMed: 12840090]

96. De Groot K, et al. Randomized trial of cyclophosphamide versus methotrexate for induction of remission in early systemic antineutrophil cytoplasmic antibody-associated vasculitis. Arthritis Rheum. 2005; 52:2461-2469. [PubMed: 16052573]

97. Stone JH, et al. Rituximab versus cyclophosphamide for ANCA-associated vasculitis. N Engl J Med. 2010; 363:221-232. [PubMed: 20647199]

98. Fulkerson PC, Rothenberg ME. Targeting eosinophils in allergy, inflammation and beyond. Nat Rev Drug Discov. 2013; 12:117-129. [PubMed: 23334207]

99. Guillevin L, et al. Prognostic factors in polyarteritis nodosa and Churg-Strauss syndrome. A prospective study in 342 patients. Medicine (Baltimore). 1996; 75:17-28. [PubMed: 8569467]

100. Kikkawa Y, et al. Interferon-a inhibits airway eosinophilia and hyperresponsiveness in an animal asthma model [corrected]. Asia Pac Allergy. 2012; 2:256-263. [PubMed: 23130331]

101. Metzler C, Csernok E, Gross WL, Hellmich B. Interferon-a for maintenance of remission in Churg-Strauss syndrome: a long-term observational study. Clin Exp Rheumatol. 2010; 28:24-30. [PubMed: 20412698]

102. Thiel J, Hassler F, Salzer U, Voll RE, Venhoff N. Rituximab in the treatment of refractory or relapsing eosinophilic granulomatosis with polyangiitis (Churg-Strauss syndrome). Arthritis Res Ther. 2013; 15:R133. [PubMed: 24286362]

103. Tsurikisawa N, et al. Treatment of Churg-Strauss syndrome with high-dose intravenous immunoglobulin. Ann Allergy Asthma Immunol. 2004; 92:80-87. [PubMed: 14756469]

104. Druilhe A, Letuve S, Pretolani M. Glucocorticoid-induced apoptosis in human eosinophils: mechanisms of action. Apoptosis. 2003; 8:481-495. [PubMed: 12975579]

105. Corren J. Inhibition of interleukin-5 for the treatment of eosinophilic diseases. Discov Med. 2012; 13:305-312. [PubMed: 22541618]

106. Kim S, Marigowda G, Oren E, Israel E, Wechsler ME. Mepolizumab as a steroid-sparing treatment option in patients with Churg-Strauss syndrome. J Allergy Clin Immunol. 2010; 125:1336-1343. [PubMed: 20513524]

107. Herrmann K, Gross WL, Moosig F. Extended follow-up after stopping mepolizumab in relapsing/ refractory Churg-Strauss syndrome. Clin Exp Rheumatol. 2012; 30(Suppl 70):S62-S65. [PubMed: 22512988]

108. US National Library of Medicine. ClinicalTrials.gov. 2014. online, http://clinicaltrials.gov/show/ NCT02020889 
109. Balding CE, Howie AJ, Drake-Lee AB, Savage CO. $\mathrm{T}_{\mathrm{H}} 2$ dominance in nasal mucosa in patients with Wegener's granulomatosis. Clin Exp Immunol. 2001; 125:332-339. [PubMed: 11529927]

110. Choopong P, et al. Eosinophil activation in Wegener's granulomatosis: a harbinger of disease progression? Ocul Immunol Inflamm. 2005; 13:439-445. [PubMed: 16321888]

111. Csernok E, et al. Cytokine profiles in Wegener's granulomatosis: predominance of type $1\left(\mathrm{~T}_{\mathrm{H}} 1\right)$ in the granulomatous inflammation. Arthritis Rheum. 1999; 42:742-750. [PubMed: 10211889]

112. Krupsky M, Landau Z, Lifschitz-Mercer B, Resnitzky P. Wegener's granulomatosis with peripheral eosinophilia. Atypical variant of a classic disease. Chest. 1993; 104:1290-1292. [PubMed: 8404215]

113. Potter MB, Fincher RK, Finger DR. Eosinophilia in Wegener's granulomatosis. Chest. 1999; 116:1480-1483. [PubMed: 10559120]

114. Schmitt WH, Linder R, Reinhold-Keller E, Gross WL. Improved differentiation between ChurgStrauss syndrome and Wegener's granulomatosis by an artificial neural network. Arthritis Rheum. 2001; 44:1887-1896. [PubMed: 11508442]

115. Schnabel A, Csernok E, Braun J, Gross WL. Activation of neutrophils, eosinophils, and lymphocytes in the lower respiratory tract in Wegener's granulomatosis. Am J Respir Crit Care Med. 2000; 161:399-405. [PubMed: 10673177]

116. Kawasaki T. Acute febrile mucocutaneous syndrome with lymphoid involvement with specific desquamation of the fingers and toes in children [Japanese]. Arerugi. 1967; 16:178-222. [PubMed: 6062087]

117. Terai M, et al. Peripheral blood eosinophilia and eosinophil accumulation in coronary microvessels in acute Kawasaki disease. Pediatr Infect Dis J. 2002; 21:777-781. [PubMed: 12192168]

118. Oner T, et al. An observational study on peripheral blood eosinophilia in incomplete Kawasaki disease. Anadolu Kardiyol Derg. 2012; 12:160-164. [PubMed: 22306569]

119. Bahrami S, Malone JC, Webb KG, Callen JP. Tissue eosinophilia as an indicator of drug-induced cutaneous small-vessel vasculitis. Arch Dermatol. 2006; 142:155-161. [PubMed: 16490843]

120. Abu-Ghazaleh RI, et al. Eosinophil granule proteins in peripheral blood granulocytes. J Leukoc Biol. 1992; 52:611-618. [PubMed: 1464733]

121. Savage CO. Pathogenesis of anti-neutrophil cytoplasmic autoantibody (ANCA)-associated vasculitis. Clin Exp Immunol. 2011; 164(Suppl 1):23-26. [PubMed: 21447127] 


\section{Review criteria}

Two reviewers independently searched MEDLINE, EMBase (from 1980) and the Cochrane Library for full-text, English-language reviews and primary literature published up to February 2014, using the following MeSH terms: "eosinophils", "eosinophilia", "vasculitis", "antibodies", "antineutrophil cytoplasmic", "Churg-Strauss syndrome", and "Wegener's granulomatosis". Additional searches combined these MeSH terms with general terms such as "pathogenesis", "clotting", "thrombosis", "vascular", "neurologic", "granule protein", “damage”, “organ involvement”, "biomarker”, “cytokine”, "chemokine", "treatment", "diagnosis" and "clinical trials". Searches were also performed using the term "eosinophilic granulomatosis and polyangiitis". The reference lists of the articles selected were also searched for additional relevant articles or research studies. 


\section{Key points}

- Eosinophils are granulocytic cells that secrete a wide variety of cytokines, chemokines and other mediators that probably have direct and indirect roles in the pathogenesis of eosinophilic granulomatosis with polyangiitis (EGPA)

- The clinical manifestations of eosinophil accumulation and activation include tissue fibrosis, thrombosis, and allergic inflammation but depend, to a large degree, on the particular tissue involved

- Although data is scarce, eosinophils seem to have a central role in disease pathogenesis in all three clinical stages of EGPA

- Clinical trials using novel therapeutic strategies that specifically target eosinophils are helping define the role of eosinophils in the pathogenesis of EGPA 


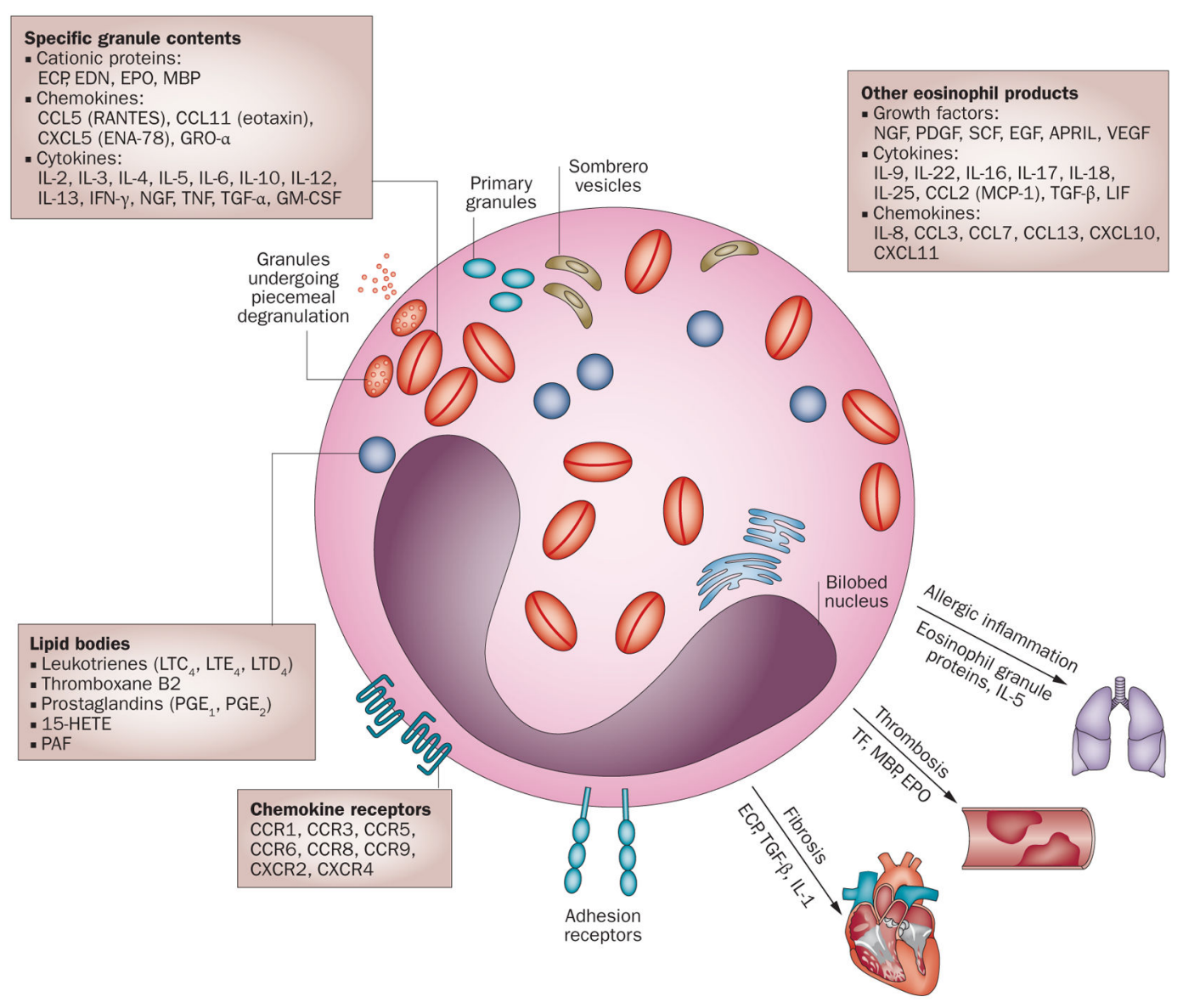

Figure 1.

Characteristics of eosinophils. Eosinophils are multifunctional, bi-lobed granulocytes that contain granular proteins including MBP, ECP, EPO and EDN. Eosinophils can degranulate by exocytosis or by piecemeal degranulation whereby individual granule contents are differentially secreted by activated eosinophils without disruption of the cell membrane. Sombrero vesicles are morphologically distinct vesicles that carry granules to the plasma membrane. Lipid bodies are structurally distinct sites within eosinophils that are responsible for synthesis of paracrine eicosanoid mediators of inflammation. Functions of eosinophils include the production of numerous chemokines, cytokines, and growth factors that mediate allergic inflammation, thrombosis, and fibrosis. A nonexhaustive list of these products are shown in boxes. Abbreviations: 15-HETE, 15-hydroxyeicosatetraenoic acid; APRIL, a proliferation-inducing ligand; CCL, CC-chemokine ligand; CCR, CC-chemokine receptor; CXCL, CXC-chemokine ligand; CXCR, CXC-chemokine receptor; ECP, eosinophil cationic protein; EDN, eosinophil-derived neurotoxin; EPO, eosinophil peroxidase; GM-CSF, granulocyte-macrophage colony-stimulating factor; GRO-a, growth regulated-a protein; LIF, leukaemia inhibitory factor; LT, leukotriene; MBP, major basic protein; NGF, nerve growth factor; PAF, platelet activating factor; PDGF, platelet-derived growth factor; SCF, stem cell factor; TF, tissue factor; TGF, transforming growth factor; VEGF, vascular endothelial growth factor. 


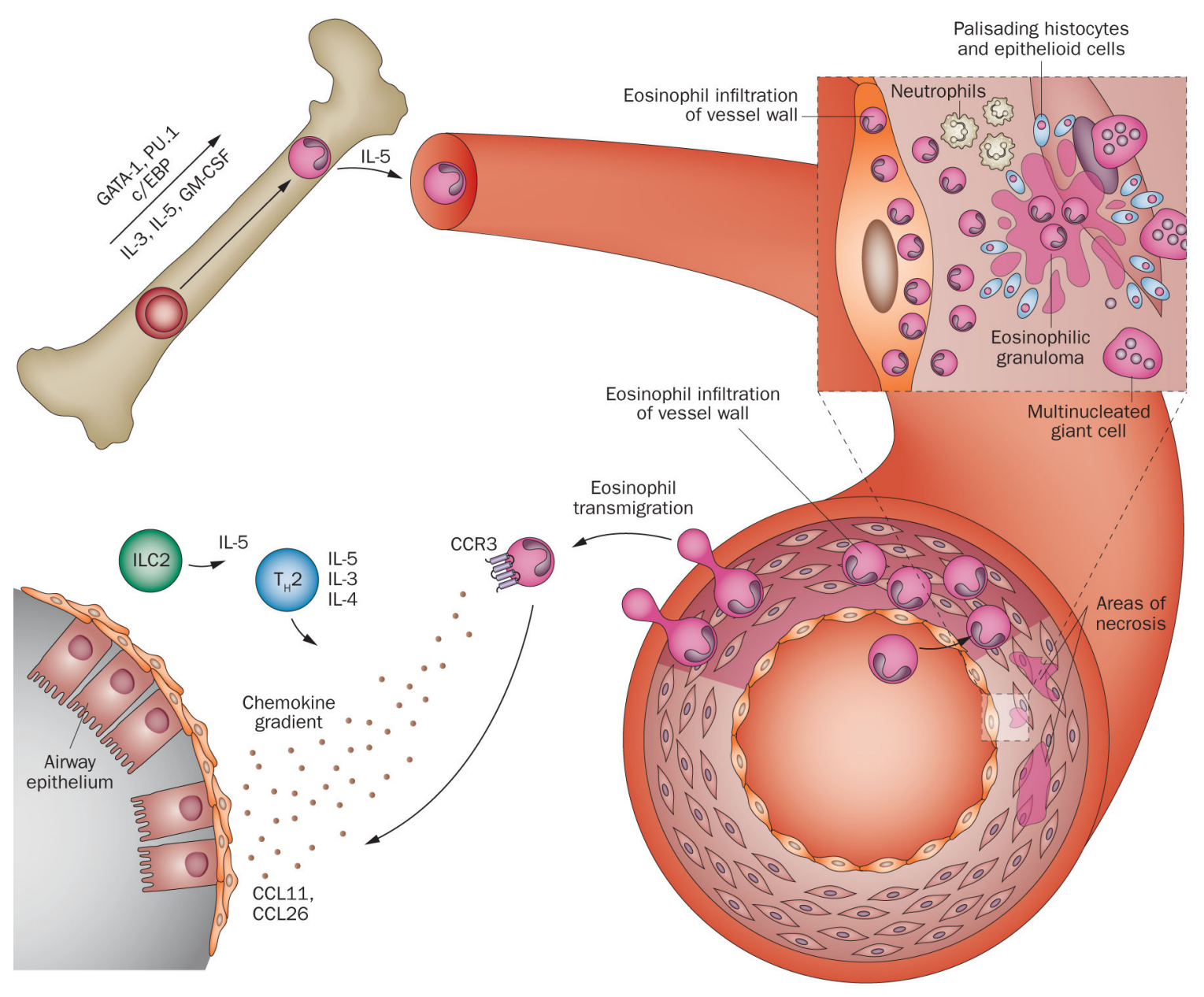

Figure 2.

Schematic representation of eosinophil trafficking. In the bone marrow, eosinophils differentiate from haematopoietic progenitor cells into mature eosinophils under the influence of transcription factors (GATA-1, PU.1, c/EBP) and their subsequent expansion is regulated by eosinophilopoietins (IL-3, IL-5, GM-CSF). Eosinophil migration into circulation is regulated primarily by IL-5. Circulating eosinophils interact with endothelial cells, migrate through the vessel wall, and infiltrate a target organ by a regulated process involving the interaction between adhesion molecules, chemokine receptors on eosinophils (CCR3) via their respective chemokine gradients (eotaxins), and cytokines (in particular products of $\mathrm{T}_{\mathrm{H}} 2$ and ILC2 cells, such as IL-4, IL-5, IL-13). The characteristic pathologic findings of eosinophil involvement in vasculitis include eosinophilic infiltration in tissue, and intravascular and extravascular granuloma formation with a zone of centralized eosinophilic necrosis and surrounding epithelioid cells, histiocytes, multinucleated giant cells, and neutrophils. Eosinophilic vasculitis of the small arteries and veins can be present, depending on the stage of disease. Abbreviations: CCL, CC-chemokine ligand; CCR, CCchemokine receptor; c/EBP, CCAAT/enhancer-binding protein; GATA-1, GATA-binding factor 1 (also known as erythroid transcription factor); GM-CSF, granulocyte-macrophage colony-stimulating factor; ILC2, type 2 innate lymphoid cell; $\mathrm{T}_{\mathrm{H}} 2$, type $2 \mathrm{~T}$ helper cell. 


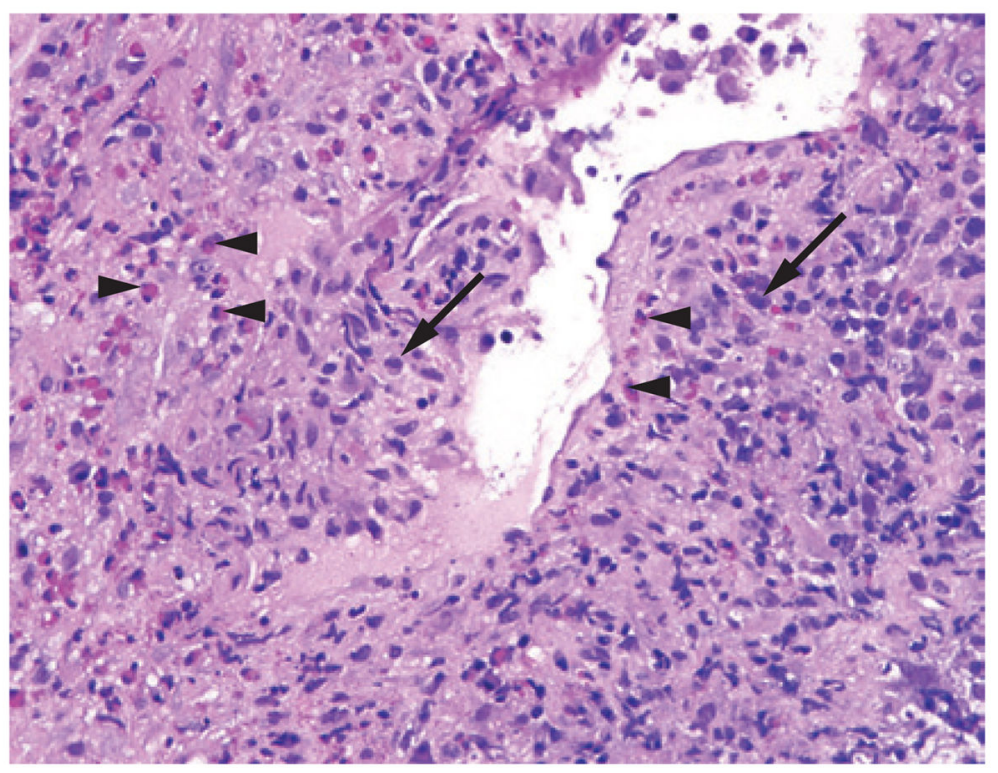

Figure 3.

Histopathology of EGPA. Biopsy-obtained transbronchial lung tissue from a patient with EGPA showing an affected blood vessel with a dense inflammatory infiltrate, composed of plasma cells (arrows) and eosinophils (arrowheads) (magnification $\times 40$ ). Abbreviation: EGPA, eosinophilic granulomatosis with polyangiitis. 
旁

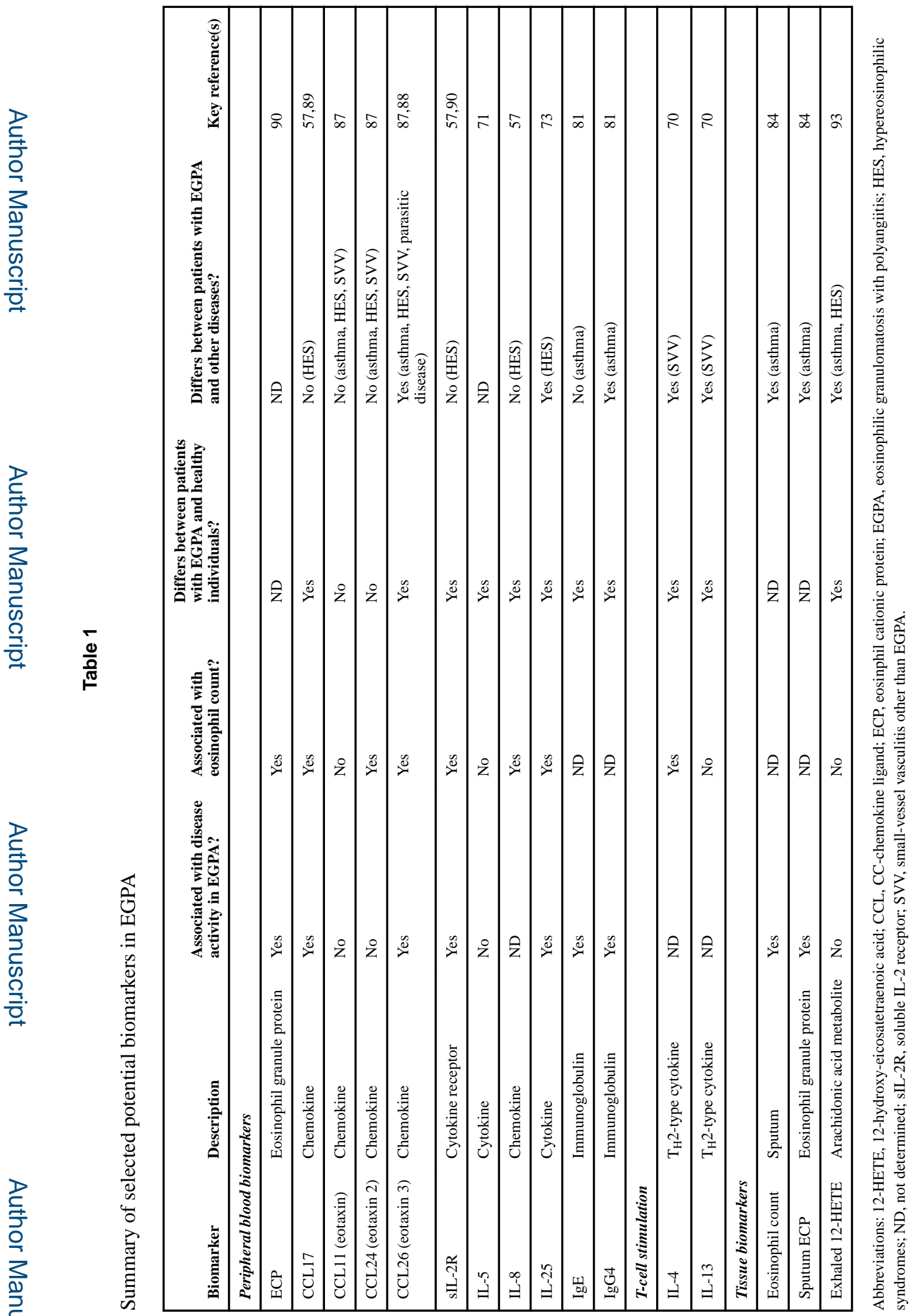

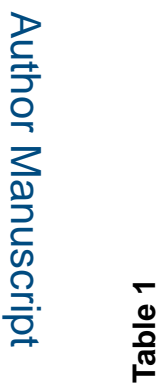

ב

Nat Rev Rheumatol. Author manuscript; available in PMC 2016 April 28. 